\title{
Combining Ability Analysis for Selected Plant Traits in Gooseberry
}

\author{
Stanisław Pluta and Edward Żurawicz \\ Fruit Breeding Department, Research Institute of Horticulture, Konstytucji 3 Maja 1/3, 96-100 \\ Skierniewice, Poland \\ Marcin Studnicki and Wiesław Madry
Department of Experimental Design and Bioinformatics, Warsaw University of Life Sciences,
Nowoursynowska 166, 02-787 Warsaw, Poland
}

Additional INDEX words. breeding value, cultivars, GCA, half-diallel mating design, Ribes grossularia, SCA, small fruit

Abstract. Gooseberry (Ribes grossularia) belongs to a group of minor fruit crops. However, in some countries such as Poland, Germany, or Scandinavia, gooseberries are cultivated on large commercial plantations. Increasing gooseberry production is of high economic interest for many gooseberry growers. Therefore, targeted gooseberry breeding for high productivity and good fruit quality, combined with resistance/tolerance to biotic and abiotic stresses, is of particular interest. A half-diallel mating design (IV Griffing's method) among 10 parental cultivars of gooseberry producing 45 sibling families was constructed to study the general and specific combining ability (GCA and SCA, respectively) effects of selected traits, which include plant vigor, plant habit, shoot thorniness, yield, plant and fruit susceptibility to powdery mildew (Sphaerotheca mors-uvae), and plant susceptibility to leaf spot (Drepanopezizia ribis). The 45 seedling families were grown at the Experimental Orchard belonging to the Research Institute of Horticulture, Skierniewice in central Poland. The experiment was planted in a randomized complete block design with three replicates (plots) each composed of 15 seedlings (the total trial included 2025 plants). Measurements and observations were recorded yearly for each seedling from 2008 to 2012 . The results showed that non-additive effects are predominantly involved in the genetic variation for all evaluated traits, whereas the additive effects play a relatively minor role in the genetic variations of these traits. Large, significant SCA effects were found for shoot thorniness, fruit weight, fruit susceptibility to powdery mildew, and plant susceptibility to leaf spot and nonsignificant variation in SCA effects was observed for the other traits (plant vigor, plant habit, fruit yield, fruit color, and plant susceptibility to powdery mildew). Significant GCA effects were limited to a few of the parents and some traits. The cultivars Worchesterberry and White Smith had good GCA effects and therefore are good parents for breeding thornless cultivars. 'Pax' and 'Martlet' are desirable genotypes for developing new cultivars with large fruit. The cultivars Martlet and Kamieniar are good parents for low fruit susceptibility to powdery mildew, and they may be efficient parents in breeding programs focused on increasing resistance/tolerance to this disease in new cultivars. Based on our results, we discuss strategies for gooseberry breeding programs and provide better insight into the genetic control of the traits studied.

In Poland, gooseberry is an important small fruit crop. Plants are grown on commercial plantations as well as in home gardens. In addition, this crop is a good supplement to the cultivation of blackcurrant (Ribes nigrum) and redcurrant (Ribes rubrum) to reduce the risk of production and expand the use of machines for the maintenance of the plantations and fruit harvests. Gooseberry fruit are eaten raw and are an excellent product for the raw freezing and food processing industries. The agro-climatic conditions of Poland are very suitable for gooseberry cultivation. Poland has been one of the biggest producers and exporters of fresh and processed gooseberry fruit in Europe and the world for many years. In the 1990s, the production of this crop was as high as 42,000 to $47,000 \mathrm{Mg}$. According to data from the Food and Agriculture Organization of the United Nations (2013), the annual domestic production of gooseberries has been very stable in recent years and ranges between 14,000 and 16,000 Mg.

The high prices of gooseberry fruit and profitability of production in Poland in the last 3 to 4 years have resulted in increased interest from our growers in new plants. However, a lack of suitable cultivars was the primary reason of declining

Received for publication 17 Dec. 2013. Accepted for publication 20 Mar. 2014. ${ }^{1}$ Corresponding author. E-mail: Stanislaw.Pluta@inhort.pl. production and is an obstacle to overcome in the development of gooseberry production. An old British gooseberry cultivar, White Smith, remains dominant in commercial cultivation. This cultivar is very valuable for its productivity, fruit size, and color, and the berries are very useful for freezing and processing as well as for machine harvesting. The main disadvantage of this cultivar is its high plant and fruit susceptibility to powdery mildew and leaf spot, and these pathogens cause serious problems in the commercial production of gooseberries (Beyer and Roser, 1989; Pluta et al., 2010). To develop new gooseberry cultivars, a basic understanding of the feasibility of selecting and breeding for the trait of interest from the available variation present in the crop germplasm is essential.

The Polish gooseberry breeding program based at the Fruit Breeding Department of the Research Institute of Horticulture (previously Institute of Pomology and Floriculture) in Skierniewice, Poland, strives to release new and valuable cultivars that are well adapted to Polish conditions (Pluta and Żurawicz, 2004; Żurawicz et al., 2000). However, gooseberry breeding has its challenges, and little information has been published on the genetic parameters and breeding strategies for gooseberry cultivar production. This process involves the optimal selection of parental material for crossing with the highest breeding values, an effective use of the genotypes of donors with desired 
traits, choice of the breeding method, and even determining the direction of crossing the parental forms.

New gooseberry cultivars, which are well adapted to the biotic and abiotic stresses of the agro-climates, cultivation practices, market, and processing requirements, may help expand the market and improve the financial return to growers. A key component of such considerations is evaluating the breeding value of candidate parents in the breeding program that is involved in developing the desired cultivars. The breeding value of parental genotypes in a quantitative trait can be appropriately assessed using their genetic parameters such as the general and specific combining ability of any given trait. The GCA of a parental genotype for the quantitative trait of interest describes the ability of that parent to transfer the trait at some average level to its half-sib progeny (Baker, 1978; Griffing, 1956a, 1956b). The GCA effect of a parent for a trait is a measure of the additive effect of that parent's genes on that trait within the gene pool of the parental genotypes involved in the mating design (Griffing, 1956a, 1956b). The GCA of the parents for a trait describes their overall use for developing new cultivars with respect to the trait. The most valuable hybrid progeny in terms of quantitative traits can be obtained by crossing parents that exhibit desirable GCA effects for these traits when the SCA has a small role in determining the genetic variation of the trait in the considered breeding population (Dosset et al., 2008; Gimenez and Ballington, 2002; Zurawicz et al., 2006). The SCA of a pair of parents for the quantitative trait of interest is the genetic interaction of both parents on that trait, which is manifested in the full-sib progeny. Therefore, the SCA effect of two parents on a trait is a measure of the effect of their genetic interaction on that trait and is the result of the nonadditive action (dominance and epistasis) of the parents' genes (Baker, 1978; Griffing, 1956a, 1956b). The probability of success in selecting the most efficient parents in a breeding program will be further enhanced if the SCA of particular parental combinations is also considered when only genetic variation exists in a breeding gene pool.

In gooseberry, very little genetic knowledge is available on the inheritance of quantitative characteristics as well as the combining abilities of potential parental genotypes such as cultivars, clones, selections, and germplasm accessions. The reasons for this lack of knowledge, like with other fruit crops (Yao and Mehlenbacher, 2000), is costly research requiring much labor and an extended period of data recording. The aim of this study was to assess genetic variation patterns of nine horticultural traits in gooseberry using a half-diallel mating design [Griffing's method 4 (Griffing, 1956b)] in a Polish agroecosystem that is suitable and typical for production of temperate fruit crops. In particular, we focused on investigating the relative importance of GCA and SCA effects in controlling the important horticultural traits. The importance and use of the findings in practical breeding of modern gooseberry cultivars adapted to Polish and European agro-ecosystems, cultivation practices, and market requirements are also discussed.

\section{Methods and Materials}

EXPERIMENTAL MATERIAL. Ten parental gooseberry cultivars (Table 1), originating from different countries and differing in horticultural traits of plant and fruit morphology and reaction to fungal diseases, were crossed in a half-diallel mating design [Griffing's method 4 (Griffing, 1956b)], and the resulting progenies were used in this experiment.

Tree fruit breeders often do not have the resources to include many parents in a diallel but still want to obtain reliable estimates of GCA effects that will be indicative of future performance for the diallel parents (Zeinanloo et al., 2009). A compromise is to select genetically broad-based material that will represent future populations (Topp et al., 1993). The gooseberry parental cultivars included in the diallel mating design have a broad agronomic and geographic basis. The crossing system can provide data to evaluate the breeding value of parental material and provide more general knowledge of the genetic variation of the studied traits in the species.

The experimental material consisted of $2025 \mathrm{~F}_{1}$ seedlings (hybrids) of gooseberry belonging to 45 cross combinations (three replicates with 15 seedlings each). Crosses were made in Spring 2004, and seedlings were produced and grown in controlled glasshouse conditions in Feb. to May 2005. The experiment was established in the field (mineral soil and a fawn floor of light clay with a $\mathrm{pH}$ of 6.0 to 6.5) located at the Experimental Orchard at Dabrowice (Research Institute of

Table 1. Country of origin, pedigree and phenotypic characteristics of 10 parental cultivars used in a gooseberry half diallel study at Skierniewice, Poland, in 2008-12.

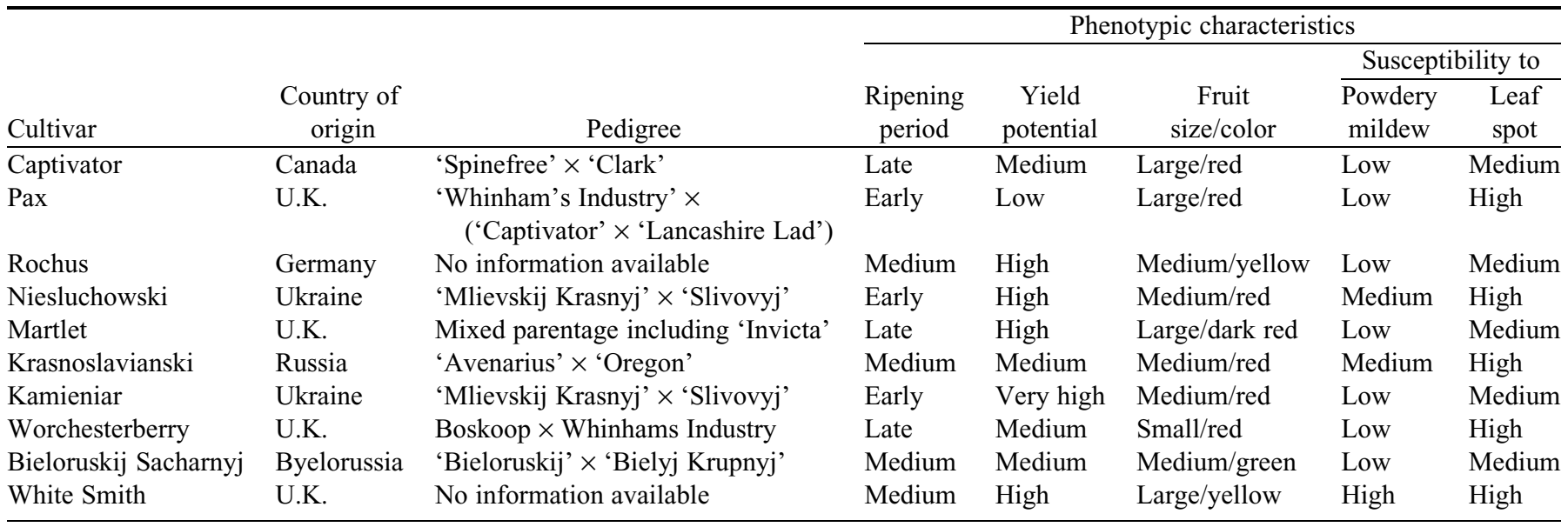


Horticulture in Skierniewice), central Poland (lat. $51^{\circ} 57^{\prime} \mathrm{N}$, long. $20^{\circ} 8^{\prime} \mathrm{E}, 125 \mathrm{~m}$ altitude) in Spring 2005. Plants were planted in a randomized complete block design with three replicates and 15 seedlings on the plot. Thus, each crossing family was represented by 45 seedlings. The seedlings were planted in rows $3 \mathrm{~m}$ apart with $0.6 \mathrm{~m}$ between the plants. Observations were collected during the 2008-12 seasons.

Traits STUDIED. Nine traits were used in this study to describe plant morphology, yield, fruit quality, and plant susceptibility to primary fungal diseases (Table 2).

The data for these traits were collected at various stages and times: early spring (March to mid-April) — shoot thorniness; spring (end of April to May) — plant vigor and plant habit; summer (June to July) — fruit yield, fruit weight, fruit color, and plant and fruit susceptibility to powdery mildew; and late summer (August to mid-September)_-plant susceptibility to leaf spot. Both the rating and metric scales for the descriptors are recommended by the International Union for the Protection of New Varieties of Plants or International Plant Genetic Resources Institute, now Bioversity International, and are used for many fruit crops such as cultivated pear [Pyrus pashia (Krause et al., 2007)], vineyard peach [Prunus persica (Nikolic et al., 2010)], almond (Prunus amygdalus), and related Prunus species (Nikoumanesh et al., 2011) as well as blackcurrant (Pluta et al., 2012).

Statistical analysis. Two types of statistical analyses of the mean plot data for agronomic traits recorded across the studied years were performed on the $F_{1}$ sibling families from the half-diallel mating design. For these analyses, years were treated as separate environments (Dosset et al., 2008). First, the analysis was performed for data collected in each test year. This approach was justified because of significant interactions of $\mathrm{GCA} \times$ year and SCA $\times$ year for some traits as concluded using the combined analysis of data from all the test years (described later). The analysis of data for each trait observed in an individual test year was based on the linear mixed model written as (Möhring et al., 2011):

$$
\mathrm{Y}_{j f m}=\mu+\mathrm{B}_{j}+\mathrm{G}_{f}+\mathrm{G}_{m}+\mathrm{S}_{f m}+\mathrm{e}_{j f m}
$$

where $\mathrm{Y}_{j f m}$ is the response (plot mean of 15 plants) of the $f m$ th hybrid family in the $j$ th block; $\mu$ is the overall mean; $\mathrm{B}_{j}$ is the random effect of the $j$ th block; $\mathrm{G}_{f}\left(G_{m}\right)$ is the random GCA effect of the $f$ th female (the $m$ th male) parent [ $f, m=1$ to the number of parents (p) and $f<\mathrm{m}$ ] that were normally and independently distributed (NID) $\left(0, \sigma_{G C A}^{2}\right) ; \mathrm{S}_{f m}$ is the random SCA effect of the $f$ th and $m$ th parents $(f \neq m) \sim \operatorname{NID}\left(0, \sigma_{S C A}^{2}\right)$; and $\mathrm{e}_{j f m}$ is the random plot error term $\sim \operatorname{NID}\left(0, \sigma_{e}^{2}\right)$. Second, a combined analysis of the diallel progeny data for each trait collected over the multiple test years was performed; i.e., the combined data were analyzed according to the following linear mixed model given by Xiang and Li (2001) and also considered by Möhring et al. (2011) and Wu and Matheson (2004):

$$
\begin{aligned}
\mathrm{Y}_{i j f m}= & \mu+\mathrm{T}_{i}+\mathrm{B}_{j(i)}+\mathrm{G}_{f}+\mathrm{G}_{m}+\mathrm{S}_{f m}+\mathrm{GT}_{f i}+\mathrm{GT}_{m i} \\
& +\mathrm{ST}_{f m i}+\mathrm{e}_{i j f m}
\end{aligned}
$$

where $\mathrm{Y}_{\text {ijfm }}$ is the response (plot mean of 15 plants) of the $f m$ th hybrid family in the $j$ th block within the $i$ th year; $\mu$ is the overall mean; $\mathrm{T}_{i}$ is the fixed effect of the $i$ th year; $\mathrm{B}_{j(i)}$ is the random effect of the $j$ th block within the $i$ th year; $\mathrm{G}_{f}\left(G_{m}\right)$ is the random GCA effect of the $f$ th female (the $m$ th male) parent $(f, m=1$ to $\mathrm{p}$ and $f<\mathrm{m}) \sim \operatorname{NID}\left(0, \sigma_{G C A}^{2}\right) ; \mathrm{S}_{f m}$ is the random SCA effect of the $f$ th and the $m$ th parents $(f \neq m) \sim \operatorname{NID}\left(0, \sigma_{S C A}^{2}\right) ; \operatorname{GT}_{f i}\left(\mathrm{GT}_{m i}\right)$ is the random interaction effect between the $f$ th female (the $m$ th male) parent and the $i$ th year $\sim \operatorname{NID}\left(0, \sigma_{G C A x \text { Year }}^{2}\right) ; \mathrm{ST}_{f m i}$ is the random interaction effect between the $f m$ th family and the $i$ th year $\sim \operatorname{NID}\left(0, \sigma_{S C A x Y e a r}^{2}\right)$; and $\mathrm{e}_{i j f m}$ is the residual random effect (plot error) $\sim \operatorname{NID}\left(0, \sigma_{e}^{2}\right)$.

The model in Eq. [2] has been used widely for diallel data analysis; for example, in strawberry [Fragaria ×ananassa (Davik and Honne, 2005)] and apple [Malus $\times$ domestica (Abe et al., 2011)]. A linear mixed model, similar to the model in Eq. [2], was used for combined (across-site) analyses of data generated from a factorial mating design in strawberry (Hasing et al., 2012). The estimation of variance components of the random effects in models, Eq. [1] and Eq. [2], was performed using the restricted maximum likelihood (REML) method (Möhring et al., 2011; Patterson and Thompson, 1971). The REML method is the most efficient method to estimate variances of effects in a linear mixed model (Crossa et al., 2010; Yang, 2010). A restricted maximum likelihood ratio test (REMLRT) was used to test the significance of the variance components. The REMLRT function test is given by $\mathrm{D}=$ $2[\log (\operatorname{Lr} 2)-\log (\operatorname{Lr} 1)]$, where $\log (\operatorname{Lr} 2)$ is the $\log$ likelihood of a model with the variance component, and $\log (\operatorname{Lr} 1)$ is the $\log$ likelihood of a model without the variance component (Gilmour et al., 2009; Wu and Matheson, 2004). This REMLRT function test is distributed as $\chi^{2}$ with $1 \mathrm{df}$.

Based on variance components of respective effects in models, Eq. [1] and Eq. [2], Cvs for these effects were calculated. Using variance components from the model in Eq. [1], narrow-sense heritability $\left(h_{n s}^{2}\right)$ and broad-sense heritability $\left(h_{b s}^{2}\right)$ were estimated on a plot-data basis according to the following formulas:

Table 2. Evaluated plant traits and the rating scales in a gooseberry half-diallel study at Skierniewice, Poland, in $2008-12$.

\begin{tabular}{ll}
\hline Trait & \multicolumn{1}{c}{ Rating scale } \\
\hline Plant vigor & $1=$ very weak, $3=$ weak, $5=$ medium, $7=$ strong, $9=$ very strong \\
Plant habit & $1=$ erect, $3=$ upright, $5=$ spreading, $7=$ drooping, $9=$ creeping \\
Shoot thorniness & $1=$ no thorns, $5=$ medium no. of thorns, $9-$ numerous no. of thorns \\
Fruit yield & $\mathrm{kg} /$ plant \\
Fruit weight ${ }^{z}$ & $1=$ fruit \\
Fruit color & $1=$ veen, $3=$ yellow, $5=$ light red, $7=$ red, $9=$ dark red, $3=$ low, $5=$ medium, $7=$ high, $9=$ very high \\
Plant susceptibility to powdery mildew & $1=$ very low, $3=$ low, $5=$ medium, $7=$ high, $9=$ very high \\
Fruit susceptibility to powdery mildew & $1=$ very low, $3=$ low, $5=$ medium, $7=$ high, $9=$ very high
\end{tabular}

${ }^{\mathrm{z}}$ Fruit weight (size) was assessed using the average weight of 10 berries randomly sampled from the total yield of each plant. 


$$
\begin{aligned}
& h_{n s}^{2}=\frac{2 \widehat{\sigma}_{G C A}^{2}}{2 \hat{\sigma}_{G C A}^{2}+\widehat{\sigma}_{S C A}^{2}+\hat{\sigma}_{e}^{2}} \\
& h_{b s}^{2}=\frac{2 \hat{\sigma}_{G C A}^{2}+\widehat{\sigma}_{S C A}^{2}}{2 \widehat{\sigma}_{G C A}^{2}+\widehat{\sigma}_{S C A}^{2}+\widehat{\sigma}_{e}^{2}}
\end{aligned}
$$

where $\widehat{\sigma}_{\mathrm{GCA}}^{2}, \widehat{\sigma}_{\mathrm{SCA}}^{2}$, and $\widehat{\sigma}_{\mathrm{e}}^{2}$ are REML-based estimates of the effect variances in the model, Eq. [1].

Based on variance components in the combined model, Eq. [2], narrow-sense heritability $\left(\bar{h}_{n s}^{2}\right)$ and broad-sense heritability $\left(\bar{h}_{b s}^{2}\right)$ were estimated on a plot-data basis that was unbiased by genotype-environment interactions as:

$$
\begin{gathered}
\bar{h}_{n s}^{2}=\frac{2 \widehat{\sigma}_{G C A}^{2}}{2 \hat{\sigma}_{G C A}^{2}+2 \hat{\sigma}_{G C A x Y e a r}^{2}+\hat{\sigma}_{S C A}^{2}+\hat{\sigma}_{\text {SCAxYear }}^{2}+\hat{\sigma}_{e}^{2}} \\
\bar{h}_{b s}^{2}=\frac{2 \widehat{\sigma}_{G C A}^{2}+\widehat{\sigma}_{S C A}^{2}}{2 \hat{\sigma}_{G C A}^{2}+2 \hat{\sigma}_{G C A x Y e a r}^{2}+\hat{\sigma}_{S C A}^{2}+\widehat{\sigma}_{\text {SCAxYear }}^{2}+\widehat{\sigma}_{e}^{2}}
\end{gathered}
$$

where $\hat{\sigma}_{G C A}^{2}, \hat{\sigma}_{S C A}^{2}, \hat{\sigma}_{G C A x Y e a r}^{2}, \hat{\sigma}_{S C A x Y e a r}^{2}$, and $\hat{\sigma}_{e}^{2}$ are REMLbased estimates of the effect variances in model, Eq. [2].

The GCA and SCA effects in both models were predicted as best linear unbiased predictors (BLUPs) (Robinson, 1991). The known properties of BLUP include maximizing the probability of obtaining a real value for random effects and minimizing the SE of predicted random effects (Robinson, 1991; Xiang and Li, 2001). A detailed analysis of the significance of the GCA and SCA effects from zero was tested using a $t$ test (Ghigeza et al., 2014; Iqbal et al., 2006) based on the proportion the BLUP values of the GCA or SCA effects to their SE. A significant GCA or SCA effect value should be 2-fold higher than the SE value of its prediction (Emrich et al., 2008; Ghigeza et al., 2014; Piepho, 2000). All computations were performed using ASReml 3.0 (Gilmour et al., 2009).

\section{Results and Discussion}

VARIANCE COMPONENTS. The variance components of the random effects in the model, Eq. [1], for each year data and in the combined model, Eq. [2], for all the studied traits and their significance are presented in Table 3 . The variances of GCA effects across the years (in the combined model) were significant for shoot thorniness, fruit weight, and fruit susceptibility to powdery mildew. Only the GCA variances for fruit susceptibility to powdery mildew were significant in each year tested. The GCA variances for shoot thorniness and fruit weight were significant in 4 of the 5 years. In the combined data analysis, the GCA variance for susceptibility to leaf spot was not significant; however, in separate years, the GCA variances were significant in 4 of the 5 years. For these four traits, SCA variances were significant both in separate years and in data averaged across the years. Based on CV (Table 3), the variation of GCA effects in each year and averaged across the years was the largest for fruit susceptibility to powdery mildew (CV was between 8.13 and 16.8) followed by shoot thorniness and fruit weight ( $\mathrm{CV}$ was $\approx 4 \%$ ). These differences were the largest among all the studied traits for which these effects showed significant variation. The largest significant variation of SCA effects was found for fruit yield $(\mathrm{CV}=$ $39.41 \%$ ) followed by fruit susceptibility to powdery mildew $(\mathrm{CV}=23.12 \%)$, but plant habit $(\mathrm{CV}=4.48 \%)$ was characterized by one of the lowest variances of these effects. Moreover, the variation in SCA effects for most of the studied traits belonged to the largest among all the modeled effects with regard to the different traits.

SCA variances were considerably greater than the GCA effects of fruit weight, shoot thorniness, susceptibility to powdery mildew on fruit, and leaf spot susceptibility. The ratios of SCA variances to GCA variances for these traits were much greater than one and were $\approx 10$ for fruit weight, from 3 to 5 for shoot thorniness and fruit susceptibility to powdery mildew, and from 2 to 3 for susceptibility to leaf spot. In addition, the broad-sense heritabilities estimated for each year and across the years for these traits were the highest (between 0.07 and 0.53 in the years and traits) (Table 4). These empirical results suggest that fruit weight, shoot thorniness, fruit susceptibility to powdery mildew, and leaf spot in gooseberry are determined genetically by both additive and non-additive effects; however, fruit weight is determined predominantly by non-additive effects. Our results are consistent with Zeinanloo et al. (2009) who found a much greater SCA effect than GCA effect on fruit weight, stone morphology, and weight and fruit oil percentage in olive (Olea europaea). The variance components of GCA effects in both models for traits including plant vigor, plant habit, fruit yield, fruit color, and plant susceptibility to powdery mildew were not significant. For these traits, SCA variances were significant in the separate years and in data averaged across the years. This result indicates that the variation of these traits in gooseberry plants is affected genetically only by non-additive effects. This conclusion is confirmed by the low narrow-sense heritabilities in each year and across the years (Table 4). These heritabilities were between 0.00 and 0.21 in the years and traits. Various authors have reported that non-additive variance is important for several horticultural characteristics of strawberry (Masny et al., 2005; Spangelo et al., 1971; Watkins and Spangelo, 1971; Żurawicz et al., 2006). Żurawicz et al. (1996) concluded that non-additive genetic variances were greater than additive variances for plant habit, plant vigor, bush size, and fruit yield in blackcurrants, similar to our findings in gooseberry plants. In blackcurrants, Żurawicz et al. (1996) found additive and nonadditive effects controlling fruit size, whereas we found predominantly non-additive effects in gooseberry plants. However, the susceptibility to important blackcurrant diseases was genetically controlled predominantly by additive effects, unlike our findings in gooseberries.

When non-additive variance is present, the most appropriate breeding method is the one that exploits all genetic variance (Watkins and Spangelo, 1968). This method can be accomplished by evaluating a large number of parental combinations (progeny testing) for identifying and selecting the best combinations for the traits of interest. In a second phase, the best seedlings of the best hybrid families should be grown on a larger scale to select the best genotypes among them. Selection in a breeding program usually involves considering several characteristics; therefore, the best crosses should combine various desirable horticultural traits (Gimenez and 


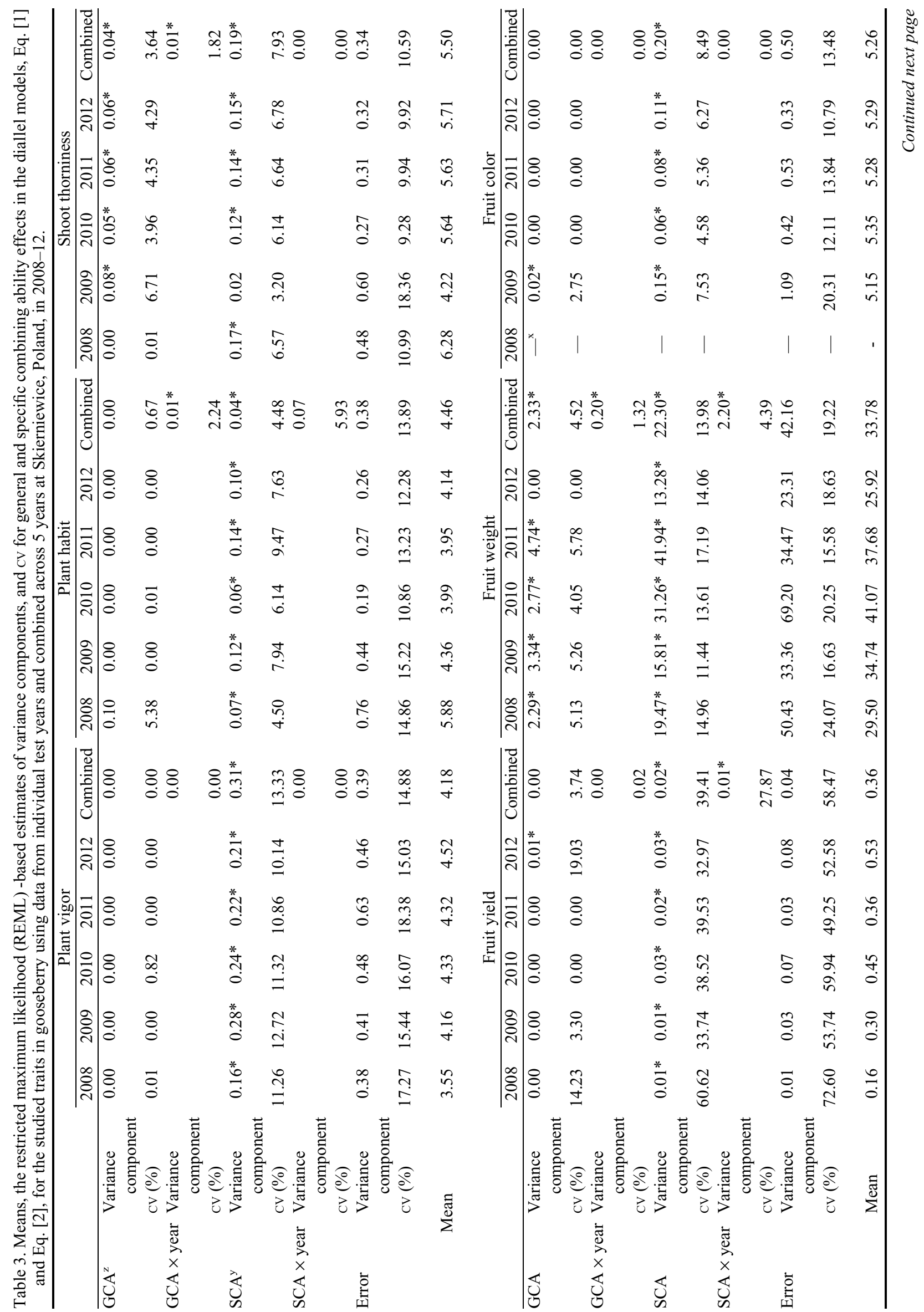




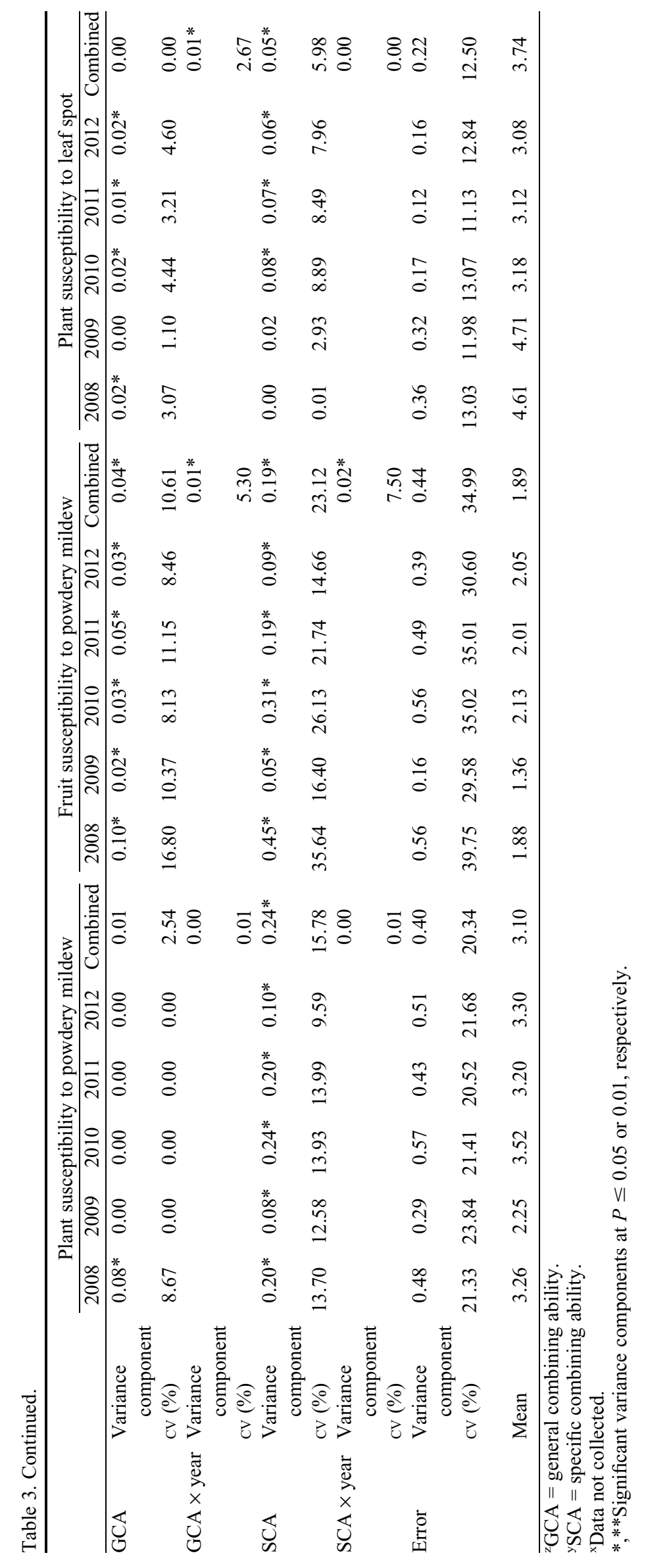


Table 4. Estimates of broad-sense $\left(h_{b s}^{2}\right.$ and $\left.\bar{h}_{b s}^{2}\right)$ and narrow-sense $\left(h_{n s}^{2}\right.$ and $\left.\bar{h}_{n s}^{2}\right)$ heritabilities for the studied traits in gooseberry using the restricted maximum likelihood (REML)-based diallel analyses at Skierniewice, Poland, in 2008-12.

\begin{tabular}{llccccccccc}
\hline & & Plant vigor & Plant habit & Shoot thorniness & Fruit yield & Fruit wt & Fruit color $^{\text {PPM }}$ & FPM $^{\mathrm{y}}$ & PLS $^{\mathrm{x}}$ \\
\hline \multirow{2}{*}{2008} & $h_{b s}^{2}$ & 0.30 & 0.26 & 0.27 & 0.40 & 0.32 & $-^{\mathrm{w}}$ & 0.43 & 0.53 & 0.08 \\
& $h_{n s}^{2}$ & 0.00 & 0.19 & 0.00 & 0.05 & 0.06 & - & 0.19 & 0.16 & 0.08 \\
\multirow{3}{*}{2010} & $h_{b s}^{2}$ & 0.40 & 0.22 & 0.23 & 0.34 & 0.40 & 0.15 & 0.22 & 0.34 & 0.07 \\
& $h_{n s}^{2}$ & 0.00 & 0.00 & 0.21 & 0.00 & 0.12 & 0.03 & 0.00 & 0.15 & 0.02 \\
& $h_{b s}^{2}$ & 0.33 & 0.25 & 0.44 & 0.26 & 0.35 & 0.13 & 0.29 & 0.40 & 0.42 \\
& $h_{n s}^{2}$ & 0.00 & 0.00 & 0.19 & 0.00 & 0.05 & 0.00 & 0.00 & 0.07 & 0.13 \\
2011 & $h_{b s}^{2}$ & 0.26 & 0.34 & 0.45 & 0.35 & 0.60 & 0.14 & 0.32 & 0.38 & 0.43 \\
& $h_{n s}^{2}$ & 0.00 & 0.00 & 0.21 & 0.00 & 0.11 & 0.00 & 0.00 & 0.14 & 0.07 \\
& $h_{b s}^{2}$ & 0.31 & 0.28 & 0.45 & 0.32 & 0.36 & 0.25 & 0.17 & 0.28 & 0.37 \\
\multirow{2}{*}{ Combined } & $h_{n s}^{2}$ & 0.00 & 0.00 & 0.20 & 0.05 & 0.00 & 0.00 & 0.00 & 0.11 & 0.12 \\
& $\bar{h}_{b s}^{2}$ & 0.44 & 0.08 & 0.45 & 0.30 & 0.38 & 0.28 & 0.39 & 0.37 & 0.18 \\
& $\bar{h}_{n s}^{2}$ & 0.00 & 0.00 & 0.14 & 0.01 & 0.07 & 0.00 & 0.02 & 0.11 & 0.00 \\
\hline
\end{tabular}

${ }^{\mathrm{z} P P M}=$ plant susceptibility to powdery mildew.

${ }^{\mathrm{y}} \mathrm{FPM}=$ fruit susceptibility to powdery mildew.

${ }^{x} P L S=$ plant susceptibility to leaf spot.

wData not collected.

Table 5. Best linear unbiased predictors (BLUPs) of the general combining ability (GCA) effects in the diallel model, Eq. [2], for the studied traits in 10 gooseberry parents obtained using the combined data generated from testing diallel progenies across 5 years at Skierniewice, Poland, in $2008-12 .^{z}$

\begin{tabular}{lcccccrrrr}
\hline Parental cultivar & Plant vigor & Plant habit & Shoot thorniness & Fruit yield & Fruit wt & Fruit color & PPM $^{\mathrm{y}}$ & FPM $^{\mathrm{x}}$ & PLS $^{\mathrm{w}}$ \\
\hline Captivator & 0.00 & 0.01 & 0.00 & 0.00 & 0.41 & 0.00 & -0.01 & 0.04 & 0.00 \\
Pax & 0.00 & 0.00 & $\mathbf{0 . 3 4}$ & 0.00 & $\mathbf{1 . 4 6}^{*}$ & 0.00 & 0.06 & $0.39^{*}$ & 0.00 \\
Rochus & 0.00 & 0.00 & 0.10 & 0.00 & -1.04 & 0.00 & 0.02 & -0.02 & 0.00 \\
Niesluchowski & 0.00 & 0.01 & 0.14 & 0.00 & 0.41 & 0.00 & 0.00 & -0.03 & 0.00 \\
Martlet & 0.00 & 0.00 & -0.04 & 0.01 & $\mathbf{1 . 7 8}^{*}$ & 0.00 & -0.06 & -0.12 & 0.00 \\
Krasnoslavianski & 0.00 & 0.00 & -0.05 & 0.00 & -0.72 & 0.00 & 0.00 & -0.10 & 0.00 \\
Kamieniar & 0.00 & -0.01 & -0.08 & 0.00 & -0.47 & 0.00 & -0.02 & -0.13 & 0.00 \\
Worchesterberry & 0.00 & 0.00 & -0.18 & 0.00 & -1.02 & 0.00 & 0.00 & -0.09 & 0.00 \\
Bieloruskij Sacharnyj & 0.00 & 0.00 & -0.04 & 0.00 & -0.38 & 0.00 & 0.02 & 0.06 & 0.00 \\
White Smith & 0.00 & -0.01 & -0.19 & 0.00 & -0.44 & 0.00 & -0.02 & 0.00 & 0.00 \\
General mean & 4.18 & 4.46 & 5.50 & 0.36 & 33.78 & 5.26 & 3.10 & 1.89 & 3.74 \\
SE of BLUPs & 0.00 & 0.03 & 0.14 & 0.01 & 0.61 & 0.00 & 0.07 & 0.07 & 0.00 \\
\hline
\end{tabular}

${ }^{\mathrm{z}}$ Bold values represent significant GCA effects in a desirable direction and identify good combiners for the studied traits.

${ }^{\text {y }} \mathrm{PPM}=$ plant susceptibility to powdery mildew.

${ }^{\mathrm{x}} \mathrm{FPM}=$ fruit susceptibility to powdery mildew.

${ }^{\text {wPLS }}=$ plant susceptibility to leaf spot.

*Significant GCA effects at $P \leq 0.05$.

Ballington, 2002). Our results are consistent with Dosset et al. (2008) who found SCA effects larger than GCA effects for fruit size in black raspberry (Rubus occidentalis). However, Dosset et al. (2008) found larger GCA effects for many phonological, vegetative, and fruit chemistry traits. With the exception of fruit size, narrow-sense heritability estimates were generally moderate to high (0.30 to 0.91$)$, indicating moderate potential for breeding progress within the studied population (Dosset et al., 2008).

The combined analysis showed that variances of interaction between GCA and year were significant for plant habit, shoot thorniness, fruit weight, fruit susceptibility to powdery mildew, and leaf spot; however, these interaction variances were smaller compared with GCA variances, especially for fruit weight. The GCA $\times$ year interactions were nonsignificant for plant vigor, fruit yield, fruit color, and plant susceptibility to powdery mildew, which are traits without significantly different GCA effects across the years. These results indicate that diversity patterns of GCA effects differed in particular years for those traits as a result of the significant GCA $\times$ year interaction. In contrast, GCA effects differed similarly (consistently) in the years for those traits that were unaffected by a significant GCA $\times$ year interaction. Variances of interaction between SCA and year were significant for plant habit, fruit yield, fruit weight, and fruit susceptibility to powdery mildew, and the interaction variances were considerably smaller than SCA variances, except for plant habit for which the SCA and SCA $\times$ year variances were comparable. The interaction variances were nonsignificant for plant vigor, shoot thorniness, fruit color, plant susceptibility to powdery mildew, and leaf spot. Generally interaction variances of GCA and SCA within 1 year were low when compared with GCA and SCA variances, and the GCA and SCA effects on average across the years were predicted accurately based on the combined model, Eq. [2] (Abe et al., 2011; Dosset et al., 2008; Yang, 2010). In black raspberries, Dosset et al. (2008) found that GCA $\times$ year and SCA $\times$ year interactions were nonsignificant for all the traits recorded. 
Table 6. Best linear unbiased predictors (BLUPs) of the specific combining ability (SCA) effects in the diallel model, Eq. [2], for the studied traits in the gooseberry parents obtained using the combined data generated from testing diallel progenies across 5 years at Skierniewice, Poland, in $2008-12 .^{\mathrm{z}}$

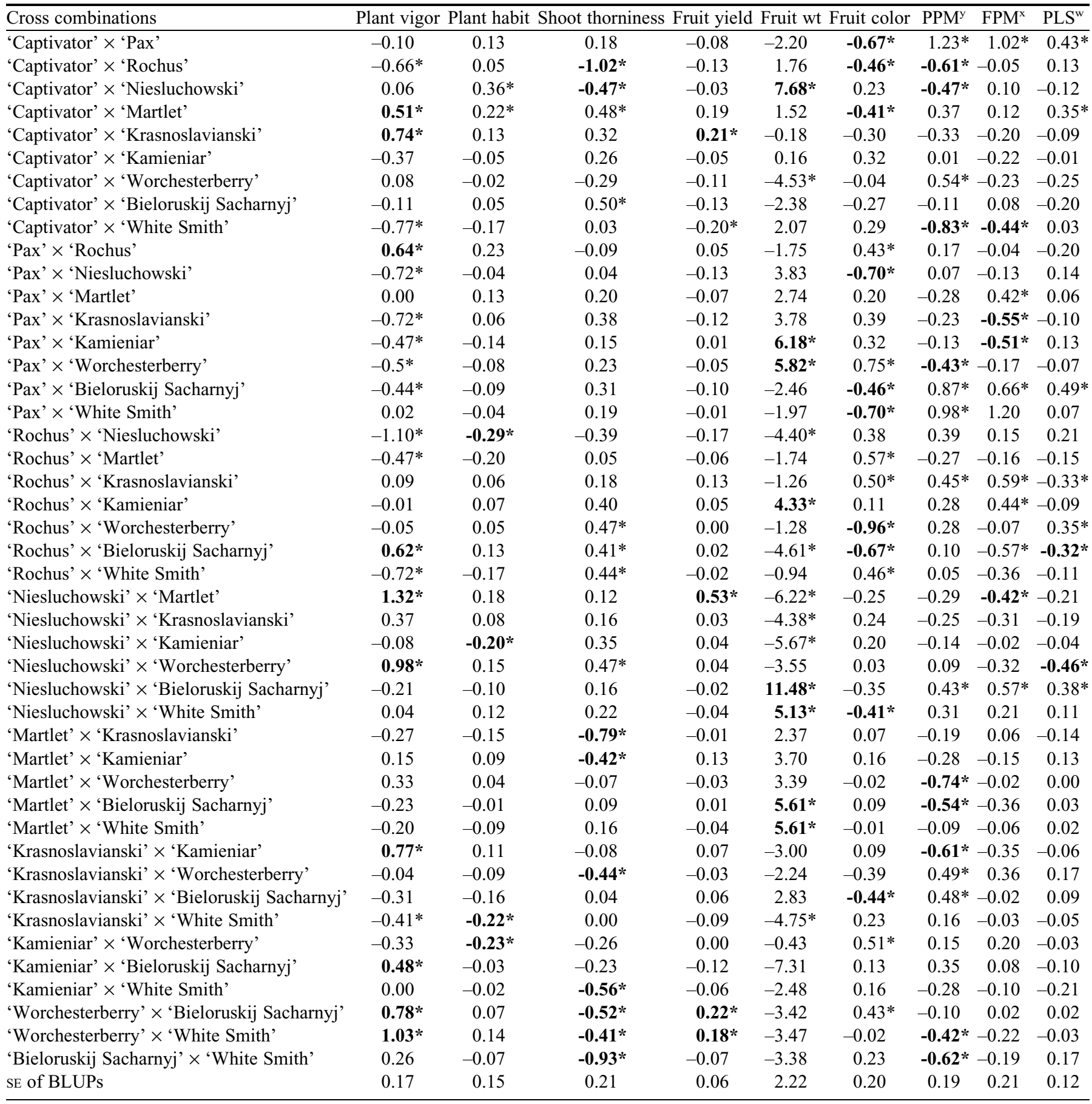

${ }^{\mathrm{z} B o l d}$ values represent significant SCA effects in the desirable direction and identify good cross combinations for the traits.

${ }^{\mathrm{y}} \mathrm{PPM}=$ plant susceptibility to powdery mildew.

${ }^{\mathrm{x}} \mathrm{FPM}=$ fruit susceptibility to powdery mildew.

${ }^{\text {wPLS }}=$ plant susceptibility to leaf spot.

*Significant SCA effects at $P \leq 0.05$.

EFfects of GCA. GCA effects of the parents refer to the average performance of a parent in hybrid combinations; i.e., half-sib families (Baker, 1978; Griffing, 1956b). A negative value of a GCA effect for a trait of the parent indicates that the hybrids involving that particular parent had a lower value for the trait than the average value of all hybrids. In contrast, a positive value of a GCA effect of a parent indicates that the hybrids of this parent had a higher value for the trait than the average value of all hybrids. The BLUPs of GCA effects for the studied traits derived from the combined model, Eq. [2], are 
presented in Table 5. The BLUPs of GCA effects for the traits are classified as good (significant values in the desirable direction of a trait scale), poor (significant values in the undesirable direction of a trait scale), and average (nonsignificant values) for the analysis of combining ability status among parents. Parents showing good GCA effects for a trait are recognized to be a good (desirable, favorable) combiner for improving trait inbreeding. In contrast, parents showing poor GCA effects for a trait are recognized to be a poor (undesirable, unfavorable) combiner for the trait. Finally, parents showing average GCA effects for a trait are recognized to be a neutral combiner for the trait. Some of the studied traits were determined using such ordinal rating scales in which hybrids showing lower values represent a more desirable horticultural value than those exhibiting higher values (e.g., plant habit, shoot thorniness, and susceptibility to fungal diseases). In contrast, other traits were expressed in ordinal rating or quantitative scales (plant vigor, fruit yield, and fruit weight) in which higher values are more desirable than a lower scale status (Table 5). Consequently, for some traits, the parental genotypes with negative GCA effects represent a useful source of genetic gain in horticultural terms.

The BLUPs of GCA and SCA effects using data from each test year obtained through the analyses based on the model, Eq. [1], are not presented in this article (as a result of the large size of the table). However, these parameters using combined data across 5 years obtained through the analysis based on the model, Eq. [2], are presented in Tables 5 and 6. For shoot thorniness, 'Worchesterberry' and 'White Smith' were found to be good combiners with significant negative GCA effects for this trait, as revealed in most years, and considerable negative GCA effects (although nonsignificant) based on the combined data from 5 years of study. 'Pax' was a poor combiner for shoot thorniness with significant positive GCA effects for each year and on average across the years. In the remaining tested parental cultivars, the GCA effects were nonsignificant for the trait both for each year and across the years; therefore, these genotypes were found to be neutral combiners for this attribute. For fruit weight, the cultivars Pax and Martlet had the highest significant positive GCA effects on average across the years and also in some separate years. This property makes the cultivars good combiners and highly useful parents for breeding new cultivars producing large fruit. Other tested cultivars had significant negative (only 'Rochus' in 1 year) or nonsignificant GCA effects for this trait, indicating their unsuitability as parents in breeding large fruit cultivars, but these cultivars are suitable as desirable parents for breeding medium or smaller fruit cultivars. For susceptibility to powdery mildew on fruit, the cultivars Martlet and Kamieniar showed the lowest negative GCA effects (nonsignificant) on average across the years, and significant negative effects were found only in some years. These cultivars are useful for gooseberry breeding programs aiming to improve this trait. This property is clearly manifested by significant positive GCA effects for this trait in all years and on average across the years. For susceptibility to leaf spot, GCA effects were rather low in the investigated years, and the effects were not significantly different on average across the years.

EFFECTS OF SCA. The SCA effect for a trait is a measure of the performance of the progeny from a cross compared with the average performance of the progeny (half-sib family) in a population (Baker, 1978; Griffing, 1956a, 1956b). Significant SCA effects for hybrid combinations indicate that the hybrid mean for a trait was higher (a positive effect) or lower (a negative effect) than would have been predicted by the GCA effects of the parents. Significant SCA effects from hybrid combinations suggest the involvement of non-additive gene effects for a trait (Iqbal et al., 2006). The BLUPs of SCA effects for all the studied traits are presented in Table 6 .

For plant vigor, despite nonsignificant GCA effects of the parents, significant positive SCA effects were identified in some hybrid combinations ('Niesluchowski' $\times$ 'Martlet', 'Niesluchowski' $\times$ 'Worchesterberry', 'Krasnoslavianski' $\times$ 'Kamieniar', 'Worchesterberry' $\times$ 'Bieloruskij Sacharnyj', and 'Worchesterberry' $\times$ 'White Smith') in all investigated years and on average across the years (Table 6). In two crosses ('Captivator' $\times$ 'White Smith' and 'Rochus' $\times$ 'Niesluchowski'), significant negative SCA effects were found for plant vigor in all years and on average across the years. Other crosses had neutral SCAs for plant vigor. We found no significant GCAs for plant vigor but found significant SCAs. This result suggests that superior selections can be made from specific crosses but that breeding progress in terms of genetic gain might be slow. For plant habit, the crosses 'Rochus' $\times$ 'Niesluchowski', 'Niesluchowski' $\times$ 'Kamieniar', 'Krasnoslavianski' $\times$ 'White Smith', and 'Kamieniar' $\times$ 'Worchesterberry' had the highest and most stable negative SCA effects in separate years, and these crosses showed the highest negative SCA effects on average across the years. These crosses could be useful in improving this trait in gooseberry breeding programs. Although the remaining cross combinations showed nonsignificant or positive SCA effects for plant habit, they were recognized to be neutral or poor for breeding. Of the 45 cross combinations, nine $\mathrm{F}_{1}$ progenies ('Captivator' $x$ 'Rochus', 'Captivator' \pm 'Niesluchowski', 'Martlet' $\times$ 'Krasnoslavianski', 'Martlet' $\times$ 'Kamieniar', 'Krasnoslavianski' $\times$ 'Worchesterberry', 'Kamieniar' $\times$ 'White Smith', 'Worchesterberry' $x$ 'Bieloruskij Sacharnyj', 'Worchesterberry' $\times$ 'White Smith', and 'Bieloruskij Sacharnyj' $\times$ 'White Smith') had significant negative SCA effects for shoot thorniness in most years and on average across the years. Of these progenies, 'Worchesterberry' and 'White Smith' also had significant GCA effects. 'Worchesterberry' and 'White Smith' are the parents involved in these cross combinations with negative SCA effects that also exhibited considerable (although nonsignificant) negative GCA effects. The progeny obtained from the crosses between parents with good and neutral GCAs for this trait produced shoots without thorns or a small number of thorns. For fruit yield, four specific cross combinations ('Captivator' $\times$ 'Krasnoslavianski', 'Niesluchowski' $\times$ 'Martlet', 'Worchesterberry' $\times$ 'White Smith', and 'Worchesterberry' $\times$ 'Bieloruskij Sacharnyj') had significant positive SCA effects. We found no significant GCA effects for fruit yield, and cross combinations that show high positive SCA effects for this trait are useful for making superior selections. As for plant vigor and habit, those cross combinations showing high positive SCA effects for this trait are useful for breeding purposes as a result of nonsignificant GCA effects. In addition, four combinations ('Captivator' $\times$ 'Niesluchowski', 'Pax' $\times$ 'Kamieniar', 'Pax' $\times$ 'Worchesterberry', and 'Niesluchowski' $\times$ 'Bieloruskij Sacharnyj') had high significant positive SCA effects recorded for fruit weight. Of these combinations, 'Pax' had a good GCA for this trait. Significant and negative SCA effects for fruit weight occurred in the majority of tested cross combinations, further suggesting the presence of strong non-additive gene action and difficulties in selecting two good parents as general combiners and hybrid combinations for this trait. 
For fruit color, the cross combinations exhibiting significant, large negative SCA effects were 'Rochus' $\times$ 'Worchesterberry', 'Captivator' $\times$ 'Pax', 'Pax' $\times$ 'Niesluchowski', 'Pax' $\times$ 'White Smith', and 'Rochus' $\times$ 'Bieloruskij Sacharnyj'. We found nonsignificant GCA effects, and the SCA effect results additionally suggested the predominance of non-additive genetic variation in fruit color within the considered gene pool. The hybrid combinations 'Captivator' $x$ 'White Smith' and 'Martlet' $x$ 'Worchesterberry' had good SCAs for low plant susceptibility to powdery mildew. The GCA effects for this trait were small and not significantly different. For low fruit susceptibility to powdery mildew, four cross combinations ('Captivator' $\times$ 'White Smith', 'Pax' $\times$ 'Krasnoslavianski', 'Pax' $\times$ 'Kamieniar', and 'Niesluchowski' $\times$ 'Martlet') showed significant negative SCA effects on average across the years. The two $F_{1}$ progenies ('Rochus' $\times$ 'Bieloruskij Sacharnyj' and 'Niesluchowski' $\times$ 'Worchesterberry') had good SCAs, showing significant negative SCA effects for susceptibility to leaf spot in most years and on average across the years.

\section{Conclusion}

This study suggests that genetic variation occurs for all the studied traits in the gooseberry gene pool and that non-additive effects are predominantly involved in this variation, especially for fruit weight. The variation in SCA effects for most of the studied traits belonged to the largest effect among the different traits. The highly significant variation of SCA effects for all the studied traits and nonsignificant (plant vigor, plant habit, fruit yield, fruit color, and plant susceptibility to powdery mildew) or significant but relatively small variation of GCA effects (for shoot thorniness, fruit weight, and susceptibility to powdery mildew on fruit and leaf spot) showed predominantly nonadditive genetic effects over additive effects. This result suggests that the mean cross performance for the studied attributes cannot be predicted accurately by the average of the GCA effects of the parents. These patterns of inheritance in the traits lead to difficulties in breeding this fruit crop and limit the genetic gain. Significant GCA effects were limited to a few of the parents for only some traits, indicating a lack of considerable heritable genetic variation in much of the gooseberry germplasm base and a need for greater diversity. On the basis of the identified GCA effects, the cultivars Worchesterberry and White Smith appeared to be good combiners and useful parents in breeding thornless cultivars, whereas 'Pax' and 'Martlet' are desirable genotypes for developing large fruit cultivars. 'Martlet' and 'Kamieniar' are good combiners for low susceptibility to powdery mildew on fruit in breeding programs for reducing the susceptibility to this disease in new cultivars. The SCA effects of crosses were rather independent of parental GCA status, but it is worth noting that some crosses showing good SCA involved one parent with a good GCA. The results allow the proper choice of parents and crosses for future gooseberry breeding programs and provide better insight into the genetic control of the traits studied. The predominant role of SCA over GCA effects in our studies indicates that breeding new gooseberry cultivars is difficult. To make this program more effective, selecting parents for a crossing program should be based on previous evaluations of SCA effects of the potential genotypes. Only pairs of genotypes that show significant and desirable (positive or negative) SCA effects should be used in a gooseberry breeding program.

\section{Literature Cited}

Abe, K., N. Kotoda, H. Kato, and J. Soejima. 2011. Genetic studies on resistance to Valsa canker in apple: Genetic variance and breeding values estimated from intra- and inter-specific hybrid progeny populations. Tree Genet. Genomes 7:363-372.

Baker, R.J. 1978. Issues in diallel analysis. Crop Sci. 18:533-536.

Beyer, E. and I. Roser. 1989. Resistant gooseberry cultivars for cultivation. Obst und Gartenbau 108:404-405.

Crossa, J., M. Vargas, and A.K. Joshi. 2010. Linear, bilinear, and linear-bilinear fixed and mixed models for analyzing genotype $\times$ environment interaction in plant breeding and agronomy. Can. J. Plant Sci. 90:561-574.

Davik, J. and B.I. Honne. 2005. Genetic variance and breeding values for resistance to a wind-borne disease [Sphaerotheca macularis (Wallr. ex Fr.)] in strawberry (Fragaria $\times$ ananassa Duch.) estimated by exploring mixed and spatial models and pedigree information. Theor. Appl. Genet. 111:256-264.

Dosset, M., J. Lee, and C.E. Finn. 2008. Genetics and breeding inheritance of phenological, vegetative and fruit chemistry traits in black raspberry. J. Amer. Soc. Hort. Sci. 133:408-417.

Emrich, K., F. Wilde, T. Miedaner, and H.P. Piepho. 2008. REML approach for adjusting the fusarium head blight rating to a phenological date in inoculated selection experiments of wheat. Theor. Appl. Genet. 117:65-73.

Food and Agriculture Organization of the United Nations. 2013. FAOSTAT. 12 Oct. 2013. <http://www.faostat.fao.org>.

Ghigeza, G., K. Mashingaidze, and P. Shanahan. 2014. Advanced cycle pedigree breeding in sunflower. II: Combining ability for oil yield and its component. Euphytica 195:183-195.

Gilmour, A.R., B.J. Gogel, B.R. Cullis, and R. Thompson. 2009. ASReml user guide release 3.0. VSN International, Hemel Hempstead, UK.

Gimenez, G. and J.R. Ballington. 2002. Inheritance of resistance to Colletotrichum acutatum Simmonds on runners of garden strawberry and its backcrosses. HortScience 37:686-690.

Griffing, B. 1956a. A generalised treatments of diallel crosses in quantitative inheritance. Heredity 10:31-50.

Griffing, B. 1956b. Concept of general and specific combining ability in relation to diallel crossing systems. Aust. J. Biol. Sci. 9:463-493.

Hasing, T., L.F. Osorio, and V.M. Whitaker. 2012. Estimation of genetic parameters and gains for color traits of strawberry. Euphytica 186:303-311.

Iqbal, M., A. Navabi, D.F. Salmon, R.C. Yang, and D. Spaner. 2006. A genetic examination of early flowering and maturity in Canadian spring wheat. Can. J. Plant Sci. 86:995-1004.

Krause, S., K. Hammer, and A. Buerkert. 2007. Morphological biodiversity and local use of the himalayan pear (Pyrus pashia) in central Bhutan. Genet. Resources Crop Evol. 54:1245-1254.

Masny, A., W. Madry, and E. Żurawicz. 2005. Combining ability analysis of fruit yield and fruit quality in ever-bearing strawberry cultivars using an incomplete diallel cross design. J. Fruit Ornamental Plant Res. 13:5-17.

Möhring, J., A.E. Melchinger, and H.P. Piepho. 2011. REML-based diallel analysis. Crop Sci. 51:470-478.

Nikolic, D., V. Rakonjac, D. Milatovic, and M. Fotiric. 2010. Multivariate analysis of vineyard peach [Prunus persica (L.) Batsch.] germplasm collection. Euphytica 171:227-234.

Nikoumanesh, K., A. Ebadi, M. Zeinalabedini, and Y. Gogorcena. 2011. Morphological and molecular variability in some Iranian almond genotypes and related Prunus species and their potentials for rootstock breeding. Sci. Hort. 129:108-118.

Patterson, H.D. and R. Thompson. 1971. Recovery of interblock information when block sizes are unequal. Biometrika 58:545-554.

Piepho, H.P. 2000. Multiple treatment comparisons in linear models when the standard error of a difference is not constant. Biometrical $\mathrm{J}$. 42:823-835. 
Pluta, S., A. Broniarek-Niemiec, and E. Żurawicz. 2010. Productive value of 18 gooseberry (Ribes grossularia L.) cultivars of different origin evaluated in central Poland. J. Fruit Ornamental Plant Res. 18:197-209.

Pluta, S., W. Mądry, and L. Sieczko. 2012. Phenotypic diversity for agronomic traits in a collection of blackcurrant (Ribes nigrum L.) cultivars evaluated in Poland. Sci. Hort. 145:136-144.

Pluta, S. and E. Żurawicz. 2004. Wykorzystanie kolekcji 'roboczej' Ribes do hodowli w Zakładzie Hodowli Roślin Sadowniczych Instytutu Sadownictwa i Kwiaciarstwa w Skierniewicach. Zeszyty Problemowe Postępów Nauk Rolniczych 497:117-123.

Robinson, G.K. 1991. That BLUP is a good thing: The estimation of random effects. Stat. Sci. 6:5-32.

Spangelo, L.P.S., C.S. Hsu, S.O. Fejer, P.R. Bedar, and G.L. Rousselle. 1971. Heritability and genetic variance components for 20 fruit and plant characters in the cultivated strawberry. Can. J. Genet. Cytol. 13:443-456.

Topp, B.L., W.B. Sherman, D.A. Huber, and S.B. Linda. 1993. Combining abilities of five japanese plum cultivars for resistance to Xanthomonas stem canker. HortScience 28:727-729.

Watkins, R. and L.P.S. Spangelo. 1968. Components of genetic variance in the cultivated strawberry. Genetics 59:93-103.

Watkins, R. and L.P.S. Spangelo. 1971. Genetic components from full, half and quarter diallels for the cultivated strawberry. Can. J. Genet. Cytol. 13:515-521.
Wu, H.X. and A.C. Matheson. 2004. General and specific combining ability from partial diallels of radiate pine: Implications for utility of SCA in breeding and deployment populations. Theor. Appl. Genet. 108:1503-1512.

Xiang, B. and B. Li. 2001. A new mixed analytical method for genetic analysis of diallel data. Can. J. For. Res. 31:2252-2259.

Yang, R.C. 2010. Towards understanding and use of mixed-model analysis of agricultural experiments. Can. J. Plant Sci. 90:605627.

Yao, Q. and S.A. Mehlenbacher. 2000. Heritability, variance components and correlation of morphological and phenological traits in hazelnut. Plant Breed. 119:369-381.

Zeinanloo, A., A. Shahsavari, A. Mohammadi, and M.R. Naghavi. 2009. Variance component and heritability of some fruit characters in olive (Olea europaea L.). Sci. Hort. 123:68-72.

Żurawicz, E., W. Mądry, and S. Pluta. 1996. Variation and heritability of economically important traits in black currant (Ribes nigrum L.) evaluated in a diallel cross design. Euphytica 91:219-224.

Żurawicz, E., A. Masny, and W. Mądry. 2006. Usefulness of selected strawberry (Fragaria $\times$ ananassa) genotypes for breeding late ripening cultivars. Acta Hort. 708:501-505.

Żurawicz, E., S. Pluta, and J. Danek. 2000. Small fruit breeding at the Research Institute of and Floriculture in Skierniewice, Poland. Acta Hort. 538:457-461. 